\title{
RESPOSTA DO ALGODOEIRO À APLICAÇÃO DE CALCÁRIO E DE CLORETO DE POTÁSSIO ${ }^{(1)}$
}

\author{
NELSON MACHADO DA SILVA (2), LUIZ HENRIQUE CARVALHO (3), Seção de Algodão, \\ RUTER HIROCE (2), Seçāo de Química Analítica, e JÚlio ISSAO KONDO (3), Seção de \\ Tecnologia de Fibras, Instituto Agronômico.
}

\section{RESUMO}

Durante cinco anos agricolas, foi conduzido ensaio permanente de calagem e adubação potássica com o algodoeiro em Latossolo Roxo, ácido, no município de Guaíra (SP) com $2,4 \%$ de matéria orgânica (M.O.), 5,1 de índice $\mathrm{pH}$ (em água); $0,4,0,8$ e $0,3 \mathrm{meq} / 100 \mathrm{~cm}^{3}$ de terra fina seca ao ar (T.F.S.A.) respectivamente de $\mathrm{Al}^{3+}, \mathrm{Ca}^{2+}$ e $\mathrm{Mg}^{2+}$, e 38 e $2 \mu \mathrm{g} / \mathrm{ml}$ de K e P. Em esquema de parcelas subdivididas, - calcário dolomítico (com poder relativo de neutralização total, PRNT, de 51,8\%) foi incorporado às parcelas nas doses de 0,2 , 4 e 6t/ha, no primeiro ano. $O$ potássio foi aplicado anualmente, nas doses de $0,50,100$ e $150 \mathrm{~kg} / \mathrm{ha}$ de $\mathrm{K}_{,} \mathrm{O}$ na forma àe cloreto. $A$ adubação básica constou de $100 \mathrm{~kg} / \mathrm{ha}$ de $\mathrm{P}_{2} \mathrm{O}_{5}$ e $50-60 \mathrm{~kg} / \mathrm{ha}$ de $\mathrm{N}$, conforme $\mathrm{o}$ ano. Na ausência de potássio, $\mathrm{o}$ efeito da calagem sobre a produção do algodoeiro foi de natureza quadrática, enquanto na presença de dose adequada do nutriente $(100 \mathrm{~kg} / \mathrm{ha}$ de $\mathrm{K}_{2} \mathrm{O}$ ) foi sempre linear. Em contrapartida, a reação das plantas a pótássio foi mais acentuada na presença de calcário, confirmando a importância de considerar o equilíbrio de bases no critério de recomendação de adubo potássico para o algodoeiro. $\mathrm{Na}$ dose mais adequada, a calagem elevou consideravelmente o nível de (Ca2+ $\left.+\mathbf{M g}^{2+}\right)$ e o pH da camada arável do solo, sendo observada uma estreita correlação positiva da produtividade com as citadas características. $O$ índice $\mathrm{pH}$ manteve-se, após o terceiro ano, na faixa de 5,8-6,0. Devido ao baixo teor original de $\mathrm{Al}^{3+} \mathrm{e}$ ao exce-

(1) Trabalho apresentado no XIX Congresso Brasileiro de Ciência cio Solo, realizado em Curitiba (PR), a 17-24 de julho de 1983. Recebido para publicação a 6 de setembro de 1983.

(2) Com boisa de suplementação, durante a fase inicial do projeto.

(3) Com bolsa de suplementação do CNPq. 
lente efeito da calagem, teria sido determinada uma subdosagem caso fosse adotado o critério de recomendação de corretivo visando apenas neutralizar o Al livre do solo. Com referência à análise química do limbo foliar, a calagem contribuiu para aumentar as concentrações de $\mathrm{Ca}$ e de $\mathrm{Mg}$ e para diminuir as de $\mathrm{K}$ e $\mathrm{Mn}$. Com a aplicação de cloreto de potássio, observou-se exatamente o inverso. Além disso, aumentou de forma sensivel a concentração de $\mathbf{C l}$. Em função da estreita correlação da produtividade com o Cl das folhas, aventou-se a hipótese de toxicidade do nutriente na dose máxima de cloreto de potássio.

\section{INTRODUÇÃO}

A reação do algodoeiro ao potássio está relacionadà ao equilibrio desse elemento com as outras bases do solo, conforme foi demonstrado em vários trabalhos experimentais $(3,4,14,15)$. Dessa forma, uma calagem em solo pobre do nutriente, se não for acompanhada de adubação adequada, pode desencadear a conhecida "fome-de-potássio" nas plantas.

Em contrapartida, se a dose de potássio nessas condições não for suficiente, deve limitar a ação do calcário. Muitas vezes, a aplicação de corretivo chega a deprimir a produção das plantas, na ausência de adubação, conforme demonstram FERRAZ (2) e SILVA (12).

Com o objetivo de estudar mais detalhadamente as inter-relações entre a calagem e a adubação potássica do algodoeiro, foi instalado um ensaio de caráter permanente, em solo ácido e pobre em potássio. São relatados e discutidos resultados obtidos em cinco anos agrícolas de condução do experimento.

\section{MATERIAL E MÊTODOS}

Em Latossolo Roxo distrófico do município de Guaíra (SP) (^), ácido e pobre em potássio para a cultura do algodoeiro, conủuziu-se ensaio permanente de calagem e adubação potássica, a partir de 1976. A análise química de amostra composta retirada antes da calagem na gleba revelou os seguintes resultados ${ }^{(\overline{)})}: 2,4 \%$ de matéria orgânica (M.O.); 5,1 de índice $\mathrm{pH} ; 0,4,0,8$ e $0,3 \mathrm{meq} / 100 \mathrm{~cm}^{3}$ de terra fina seca ao ar (T.F.S.A.), respectivamente de $\mathrm{Al}^{3+}, \mathrm{Ca}^{2+}$ e $\mathrm{Mg}^{2+}$, e 38 e $2_{\mu} \mathrm{g} / \mathrm{ml}$ de K e P.

O plano experimental constou de dezesseis tratamentos com quatro repetiçōes em um esquema de parcelas subdivididas, corn ciistribuição em blocos ao acaso. O calcário, nas doses de $0,2,4$ e 6t/ha ocupou as par-

(4) Gleba pertencente à Prefeitura Municipal. Agradecimentos são devidos a essa entidade e ao Sr. Hirofume Kage pela valiosa colaboracão prestada.

(5) Análises efetuadas na Secão de Fertilidade do Solo do Instituto Agronômico, Campinas. Indice $\mathrm{pH}$, em $\mathrm{H}_{2} \mathrm{O}$ e $\mathrm{P}$ extraido por $\mathrm{H}_{2} \mathrm{SO}_{4}$ diluído. 
celas e o adubo potássico, nas doses de $0,50,100$ e $150 \mathrm{~kg} /$ ha de $\mathrm{K}_{2} \mathrm{O}$, as subparcelas. O canteiro experimental constou de quatro linhas de $5 \mathrm{~m}$, espaçadas de $0,80 \mathrm{~m}$ entre si. $\mathrm{Na}$ operação de desbaste, foram deixadas cerca de sete plantas por metro linear. A variedade de algodão utilizada foi a 'IAC 18'.

A adubação básica de plantio, a cada ano, constou de $10 \mathrm{~kg} /$ ha de $\mathrm{N}$ e $100 \mathrm{~kg} /$ ha de $\mathrm{P}_{2} \mathrm{O}_{5}$, acrescida da dose correspondente de potássio. A partir do quarto ano-agrícola, a dose de $150 \mathrm{~kg} / \mathrm{ha}$ de $\mathrm{K} . \mathrm{O}$ passou a ser fornecida parceladamente $e$, depois do quinto ano, adicionou-se boro à adubação de plantio, na base de $1,5 \mathrm{~kg} / \mathrm{ha}$. Sulfato de amónio, superfosfato simples, cloreto de potássio e bórax foram os produtos comerciais usados.

A adubação em cobertura, nos dois primeiros anos, 1orneceu $40 \mathrm{~kg} / \mathrm{ha}$ de N. A partir do terceiro ano agrícola, essa dose î̀i elevada para $50 \mathrm{~kg} /$ ha de $\mathrm{N}$, mais $50 \mathrm{~kg} / \mathrm{ha}$ de $\mathrm{K}_{2} \mathrm{O}$, referentes ao parcelamento da dose máxima de potássio $\left(150 \mathrm{~kg} / \mathrm{ha}\right.$ de $\left.\mathrm{K}_{2} \mathrm{O}\right)$. Utilizaram-se us mesmos produtos da adubação básica.

Em 25 de agosto de 1976, cerca de dois meses antes do primeiro plantio, procedeu-se à calagem, tendo sido o calcário aplicado a lanço, sobre o solo previamente arado e gradeado, de modo convencional A incorporação do corretivo se fez com a passagem da enxada rotativa. Nos anos seguintes, o preparo do solo foi efetuado com o uso desse implemento, após passagem de escarificador, quando uma maior compactação assim exigiu. A análise química do corretivo revelou concentraçōes de $22,4 \%$ de $\mathrm{CaO}$ e $17,1 \%$ de $\mathrm{MgO}$. Na análise granulométrica, cerca de $5,6 \%$ do material ficou retido na peneira 10 e $52,7 \%$ na peneira 50, enquanto uma fração de apenas $41,7 \%$ passou pela peneira $50^{(6)}$, o que demonstra tratar-se de calcário dolomítico, grosseiro $(\mathrm{PRNT}=51,8 \%)$.

$\mathrm{O}$ efeito da calagem sobre as características químicas do solo foi acompanhado através de amostragens periódicas da área experimental, efetuadas fora das linhas de adubação, na fase de pleno desenvolvimento das plantas. Foram efetuadas três amostragens por subparcela, à profundidade de $0-20 \mathrm{~cm}$ em todos os anos, e também à profundidade de $20-40 \mathrm{~cm}$ a partir do segundo ano, perfazendo doze pontos por repetiçäo e por nível de calcário. Na coleta das amostras superficiais, utilizou-se trado tipo "holandês", e, na das mais profundas, foi usado trado comum, de rosca, tomando-se o devido cuidado para que o primeiro orifício sempre estivesse bem aberto.

Foram efetuadas análises de variância dos dados de produção obtidos em cinco sucessivos anos agrícolas e de análises químicas de folhas,

(6) Análise efetuada na Seção de Fertilidade do Solo do Instituto Agronômico, Campinas. 
colhidas por ocasiāo do florescimento, a partir do segundo ano agricola. $\mathrm{Na}$ análise do limbo foliar foram determinados durante esses anos, $\mathrm{N}$, $\mathrm{P}, \mathrm{K}, \mathrm{Ca}, \mathrm{Mg}, \mathrm{Fe}, \mathrm{Mn}, \mathrm{Cu}, \mathrm{Zn}$ e $\mathrm{B}$ e, nos últimos dois anos, também o $\mathrm{Cl}$.

Foi efetuado um estudo de correlação entre resultados de produção e dados da análise química do solo e das folhas que mais se destacaram, quais sejam $\mathrm{pH}$ e $\left(\mathrm{Ca}^{2+}+\mathrm{Mg}^{2+}\right)$ no primeiro caso e $\mathrm{Cl}$ ro segundo.

\section{RESULTADOS E DISCUSSÃO}

\subsection{Análise Química do Solo}

Das caracteristicas químicas analisadas, o índice pH e os teores de $\mathrm{Al}^{3-}, \mathrm{Ca}^{2+}$ e $\mathrm{Mg}^{2+}$ foram as mais afetadas pela calagem, conforme quadro 1.

Cinco meses após a aplicação do corretivo, ou seja, durante o pleno desenvolvimento do algodoeiro no primeiro ano agrícola, já eram notados os primeiros efeitos benéficos da calagem na camada superficial do solo. Pode-se observar que os valores de $\mathrm{pH}$ e os teores de $\mathrm{Ca}^{2+}$ e de $\mathrm{Mg}^{2+}$ acusaram aumentos sensiveis, enquanto $\mathrm{o} \mathrm{Al}^{3+}$, que originalmente eru muito baixo, não sofreu maiores variações no início. A partir do segundo ano, nas parcelas testemunhas $o$ teor de $\mathrm{Al}^{3+}$ se aproximou de $0,5 \mathrm{meq} / 100 \mathrm{~cm}$. No aspecto estatístico a testemunha sempre apresentou teor de $\mathrm{Al}^{3+}$ superior ao dos tratamentos calcariados, notando-se que, nestes, o teor se manteve em níveis insignificantes mesmo na menor calagem. Em trabalhos anteriores, conduzidos com algodão e soja, observou-se que com quantidades mínimas de calcário foi possível eliminar a nocividade do $\mathrm{Al}^{\mathrm{s}+}$ no solo $(\mathbf{1 0}, \mathbf{1 4})$. Confirma-se, mais uma vez, que a sugestão de se calcular a necessidade de calagem em função do Al trocável, proposta por alguns autores $(1,6)$, não parece ser adequada para Latossolo Roxo.

Com o uso das maiores doses de corretivo, o índice $\mathrm{pH}$ da camada arável cresceu sensivelmente nos dois primeiros aros, como demonstra a figura 1(a). A partir de então, manteve-se na faixa di 5,8 a 6,0 no tratamento com $6 \mathrm{t} / \mathrm{ha}$ de calcário, e de 5,4 a 5,5 no tratamento com $4 \mathrm{t} / \mathrm{ha}$. Na dose mínima (2t/ha), pouca variação houve, enquanto nas parcelas testemunhas $\mathrm{o} \mathrm{pH}$ caiu paulatinamente.

Quanto ao teor de $\mathrm{Ca}^{*-}$ na camada $0-20 \mathrm{~cm}$, o tratamento com dose máxima de calcário superou a testemunha desde o primeiro ano, conforme quadro 1. Assim ocorreu, também, com a dose de $4 \mathrm{t} / \mathrm{ha}$ a partir do segundo ano, enquanto a dose de $2 \mathrm{t} /$ ha só se destacou no último ano agrícola. Fato semelhante se deu com o $\mathrm{Mg}^{2+}$ na camada superficial, razão por que na figura 1 (b) os dois nutrientes são apresentados em conjunto. Embora a soma dessas bases tenha aumentado continuamente até o quarto ano agricola para os tratamentos fornecedores de 4 e $6 \mathrm{t} / \mathrm{ha}$ de corretivo, houve destaque para os acréscimos iniciais. 
QUADRO 1. Resuitados de análises de solos de amostras coletadas a duas profundidades, no ensaio permanente de calagem e de adubação potássica do algodoeiro, e valores das análises de variância e dos coeficientes de correlação simples (r) para cada característica

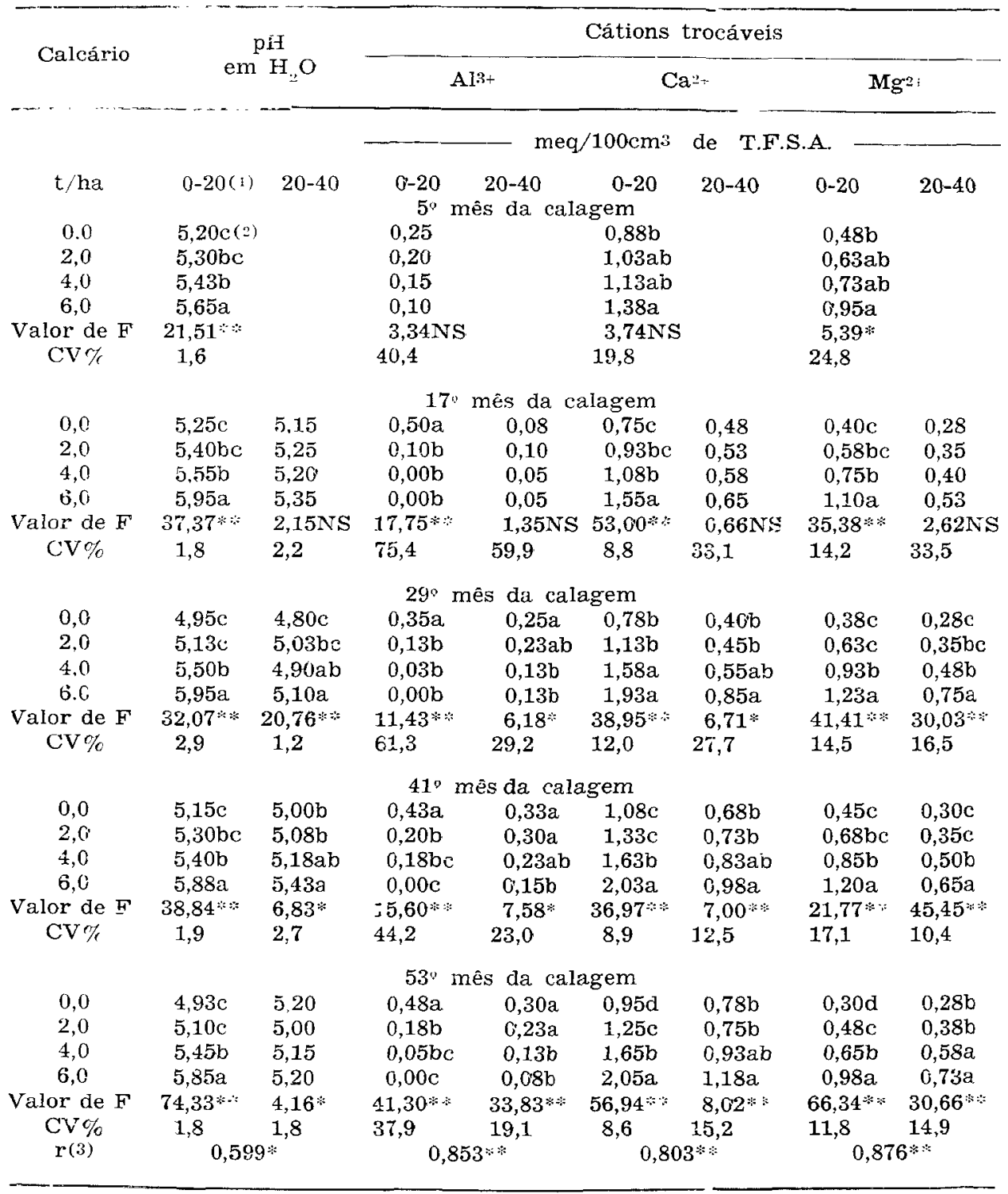

(1) Amostras colhidas por nível de calagem e por repetição às profundidades de 0 a $20 \mathrm{~cm}$ e de 20 a $40 \mathrm{~cm}$. (2) Letras não comuns, em uma mesma coluna, indicam diferenças significativas pelo teste de Tukey, a 5\%. (3) Valores obtidos no estudo de correlação simples entre as médias dos valores das características químicas observadas nas duas profundidades, durante os últimos quatro anos de efeito da calagem. 

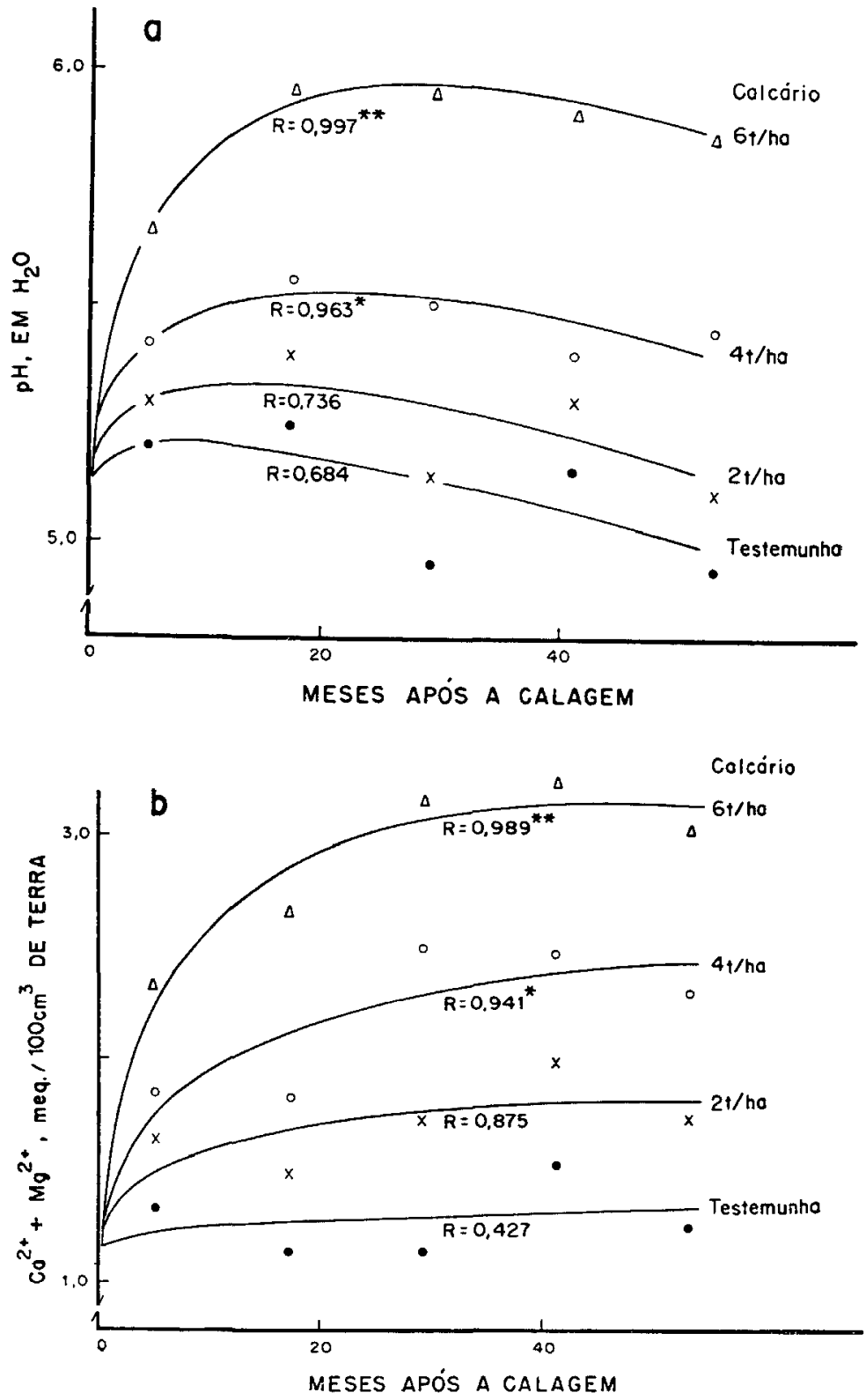

FIGURA 1. Variações no índice pH, em água (a) e nos teores de $\mathrm{Ca}^{2+}+\mathbf{M g}^{2+}$ (b) da análise química da camada superficial do solo, em função da calagem. 
Em outros trabalhos, demonstrou-se que as maiores alteraçōes em certas características químicas do solo ocorrem no primeiro ou segundo ano da calagem $(2,10,11,14)$, podendo os efeitos sobre o pH do solo, quando do uso de calcário grosseiro, estenderem-se além do segundo ou terceiro ano agrícola $(\mathbf{1 0}, \mathbf{1 1})$. No presente caso, a melhoria se manteve até o quinto ano, na maior dose do corretivo, o que não ocorreu em trabalhos anteriores, em solos de mais alta capacidade de troca catiônica (C.T.C.), quando o índice $\mathrm{pH}$ declinou após o terceiro ano, mesmo na presença de $6 \mathrm{t} / \mathrm{ha}$ de calcário $(2,14)$.

Para uma análise do que ocorreu na camada mais profunda do solo $(20-40 \mathrm{~cm})$, ainda no quadro 1 , nota-se que no segundo ano agrícola, já houve tendência para alterações nos resultados analíticos em função da calagem. No aspecto estatístico, tais modificaçōes se tornaram evidentes a partir do terceiro ano, em particular para o $\mathrm{Mg}^{2-}, \mathrm{Al}^{3+}$ e $\mathrm{Ca}^{2+}$. Um estudo de correlação simples entre teores analíticos méciios observados nas duas camadas $(0-20$ e $20-40 \mathrm{~cm})$, revelou valores de " $r$ " altamente significativos para $\mathrm{Mg}^{2+}, \mathrm{Al}^{3+}$ e $\mathrm{Ca}^{2+}$, e apenas significativo para o índice $\mathrm{pH}$. Os dados confirmam que o arrastamento de $\mathrm{Ca}^{2+}$ a de $\mathrm{Mg}^{2+}$ fornecidos pelo calcário dolomítico, para camadas mais profundas do solo, ocorre de forma lenta, porém constante e gradual, sendo de maior expressão para o $\mathrm{Mg}^{2+}(9,10,11,14)$.

\subsection{Dados de Produção}

O efeito médio da calagem sobre a produção das plantas foi altamente significativo e de natureza linear, em todos os anos do estudo, conforme quadro 2 .

Nas análises anuais, a dose mínima de calcário (2t/ha) nunca diferiu estatisticamente da testemunha, enquanto a máxima (6t/ha) sempre a superou. Determinou-se uma estreita correlação entre a produtividade e as características de solo mais afetadas pela prática da caiagem, ou seja, $\mathrm{o}$ indice $\mathrm{pH}$ e a soma de bases $\left(\mathrm{Ca}^{2+}+\mathrm{Mg}^{2+}\right)$, conforme figura 2 .

Para o estudo em questão, foram utilizados resultados do terceiro ano agrícola, quando o efeito da calagem já estava bem definido. Pela análise da figura 2(a), nota-se que a produtividade cresce continuamente com o aumento do $\mathrm{pH}$, tendo sido necessário extrapolar para cálculo do ponto de máxima $(\mathrm{pH}=6,4)$. De forma mais abrupta ainda, a produtividade acompanhou o crescimento dos valores de $\left(\mathrm{Ca}^{4+}+\mathrm{Mg}^{2+}\right)$ do solo, com um máximo sendo estimado por volta de 6,8 , conforme figura 2(b). A granulometria extremamente grosseira do calcário talvez explique não só o aumento gradativo das bases no solo, através dos anos, como também o fato de não se ter alcançado valores de $\mathrm{pH}$ superiores a 6,0 .

A reação das plantas ao cloreto de potássio, embora sempre significativa, ocorreu de forma quadrática, conforme quadro 2 . Nota-se, de 
QUADRO 2. Resultados médios de produção de algodão em caroço ( $\mathrm{kg} / \mathrm{ha}$ ) correspondentes aos diferentes níveis de calagem e de adubação potássica, assim como dados de respectivas análises de variancia obtidos nos cinco primeiros anos de condução de ensaio permanente, em Guaíra (SP)

\begin{tabular}{|c|c|c|c|c|c|c|c|}
\hline \multicolumn{2}{|c|}{ Calcário } & \multicolumn{6}{|c|}{$\mathrm{K}, \mathrm{O} \quad(\mathrm{kg} / \mathrm{ha})$} \\
\hline Doses & $\begin{array}{l}\ll \mathbf{F} » \\
\text { linear }\end{array}$ & 0 & 50 & 100 & 150 & Media & $\begin{array}{c}\langle\mathbf{F} » \\
\text { quadr. }\end{array}$ \\
\hline \multicolumn{2}{|l|}{$\mathrm{t} / \mathrm{ha}$} & \multicolumn{6}{|c|}{$1976 / 77(\mathrm{CV}=21,5 \%)$} \\
\hline 0,0 & & 1006 & 1238 & 1281 & 1110 & $1159 \mathrm{c}(1)$ & \\
\hline 2,0 & & 1319 & 1641 & 1654 & 1504 & $1529 \mathrm{bc}$ & \\
\hline 4,0 & & 1923 & 2025 & 2341 & 2041 & $2083 a b$ & \\
\hline 6,0 & & 1879 & 2273 & 2654 & 2685 & $2373 a$ & \\
\hline \multirow[t]{2}{*}{ Média } & $29,68 *$ & $1532 b(1)$ & $1794 a b$ & $1983 a$ & $1835 \mathrm{ab}$ & 1786 & $4,56^{*}$ \\
\hline & & \multicolumn{6}{|c|}{$1977 / 78(\mathrm{CV}=19,0 \%)$} \\
\hline 0,0 & & 735 & 1038 & 1119 & 850 & $936 \mathrm{~b}$ & \\
\hline 2,0 & & 906 & 1310 & 1313 & 1216 & $1186 \mathrm{ab}$ & \\
\hline 4,0 & & .1388 & 1550 & 1648 & 1550 & 1534ab & \\
\hline 6,0 & & 1248 & 1804 & 2054 & 1925 & $1758 \mathrm{a}$ & \\
\hline \multirow[t]{2}{*}{ Média } & $21,35^{*}$ & 10693 & $1426 a$ & $1534 a$ & $1385 a$ & 1354 & $15,37 \%$ \\
\hline & & \multicolumn{6}{|c|}{$1978 / 79(\mathrm{CV}=18,6 \%)$} \\
\hline 0,0 & & $60 \pm$ & 1066 & 1156 & 1000 & $957 \mathrm{~b}$ & \\
\hline 2,0 & & 754 & 1344 & 1579 & 1269 & $1237 \mathrm{~b}$ & \\
\hline 4,0 & & 1323 & 1848 & 2300 & 1794 & $1816 a$ & \\
\hline 6,0 & & 1256 & 2198 & 2731 & 2454 & $2160 \mathrm{a}$ & \\
\hline \multirow[t]{2}{*}{ Média } & $63,81 *$ & $984 \mathrm{c}$ & $1614 \mathrm{~b}$ & $1942 \mathrm{a}$ & $1629 b$ & 1542 & $43,21 * *$ \\
\hline & & \multicolumn{6}{|c|}{$1979 / 80(\mathrm{CV}=19,8 \%)$} \\
\hline 0,0 & & 1085 & 1948 & 1760 & 1363 & $15.9 \mathrm{c}$ & \\
\hline 2,0 & & 1388 & 2248 & 2169 & 1938 & $1936 \mathrm{bc}$ & \\
\hline 4,0 & & 2125 & 2913 & 3338 & 2254 & $2658 \mathrm{ab}$ & \\
\hline 6,0 & & 1906 & 3313 & 3760 & 2913 & $2973 a$ & \\
\hline \multirow[t]{2}{*}{ Média } & $32,30 * *$ & $1626 c$ & $2606 \mathrm{a}$ & $2757 a$ & $2117 \mathrm{~b}$ & 2277 & $51,44 * *$ \\
\hline & & \multicolumn{6}{|c|}{$1980 / 81(\mathrm{CV}=14,9 \%)$} \\
\hline 0,0 & & 1148 & 1844 & 1998 & 1694 & $1671 \mathrm{~b}$ & \\
\hline 2,0 & & 1156 & 2100 & 2194 & 2110 & $1890 \mathrm{ab}$ & \\
\hline 4,0 & & 1931 & 2404 & 2673 & 2554 & $2: 91 a b$ & \\
\hline 6,0 & & 1650 & 2575 & 2916 & 2760 & $2475 a$ & \\
\hline Média & $15,07 * *$ & $1471 \mathrm{~b}$ & $2231 \mathrm{a}$ & $2445 \mathrm{a}$ & $2280 \mathrm{a}$ & 2107 & $34,77 * \%$ \\
\hline
\end{tabular}

(1) Letras não comiuns simbolizam classes estatísticas diferentes, pelo teste de Tukey, a $5 \%$. 

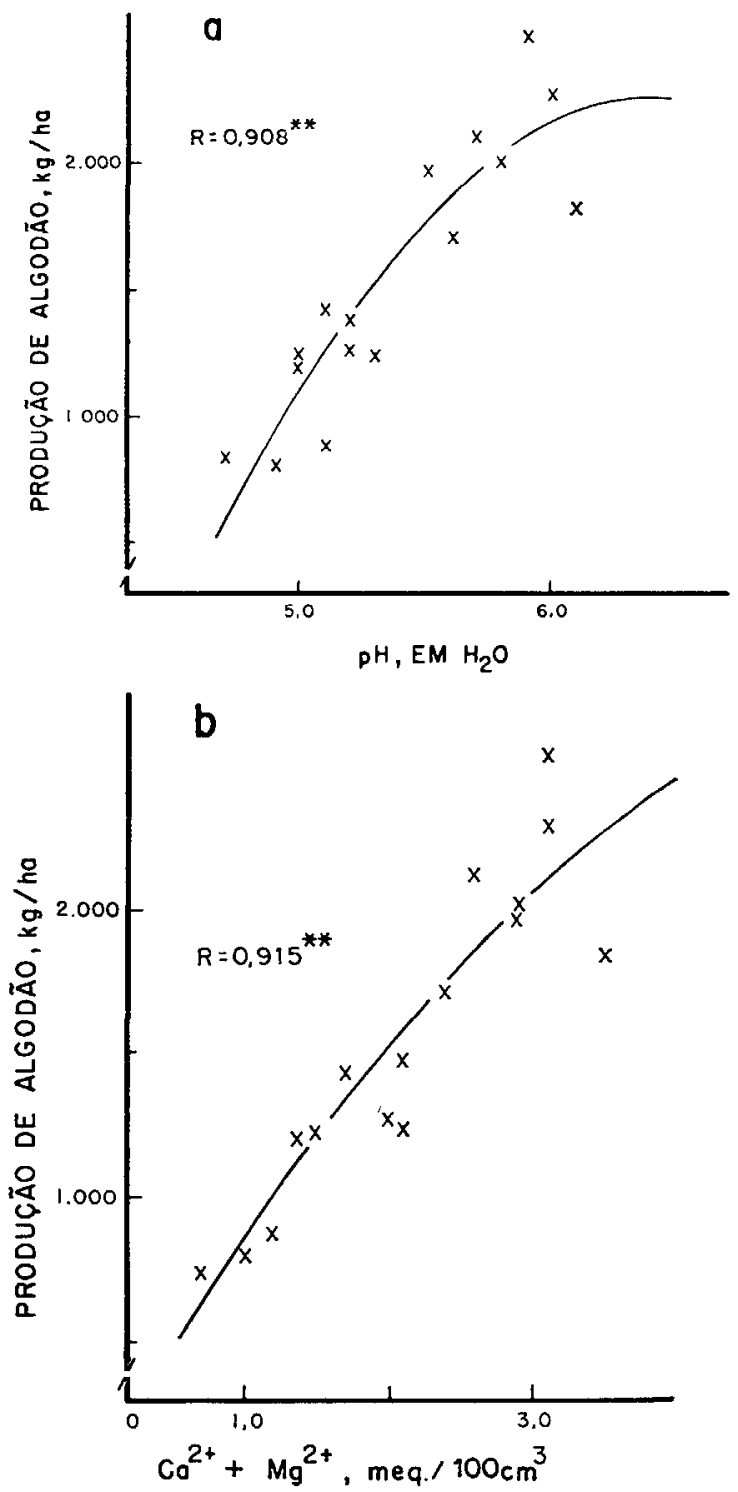

FIGURA 2. Relação entre produção de algodão em caroço e $\mathrm{pH}$, em $\mathrm{H}_{2} \mathrm{O}$ (a) e entre prođução e soma de bases $\mathrm{Ca}^{2+}+\mathrm{Mg}^{2+}$ (b) da análise da camada superficial do solo.

fato, que a produtividade cresceu até o nível de $100 \mathrm{~kg} /$ ha de $\mathrm{K}_{2} \mathrm{O}$, cainơo na última dose de adubo, em todos os anos.

Quanto às interações, observou-se que a produção de algodão aumentou de forma linear e significativa com a calagem, quando em presença 
de potássio, em especial da dose de $100 \mathrm{~kg} /$ ha de $K_{2} \mathrm{O}$. Já na ausência de adubação, os acréscimos foram menores, de natureza quadrática e raramente significativos. Para melhor visualizar essa interação, foram traçadas curvas médias de produção (figura 3), calculadas em função da calagem, na ausência e na presença de potássio $\left(100 \mathrm{~kg} /\right.$ ha de $\left.\mathrm{K}_{2} \mathrm{O}\right)$.

$\mathrm{Na}$ ausência de potássio, foi possivel estimar a máxima produção esperada, de $1.650 \mathrm{~kg} /$ ha de algodão em caroço, que corresponderia à aplicação aproximada de 6t/ha de calcário. Em presença de adequada adubação, no entanto, a produção aumentou linearmente com a calagem, de forma a não ser possível estimar a dose de calcário para máxima produção. Entretanto, o nivel de produtividade esperado seria bem mais elevado, nessa situação. Fica assim mais uma vez demonstrado que, em condição de deficiência potássica, a ação da calagem pode em certa extensão ser bloqueada por inadequada adubação $(\mathbf{2}, \mathbf{1} 2)$.

A reação das plantas a potássio nos dois primeiros anos foi significativa apenas na presença de $6 \mathrm{t} / \mathrm{ha}$ de calcário, conforme dados do

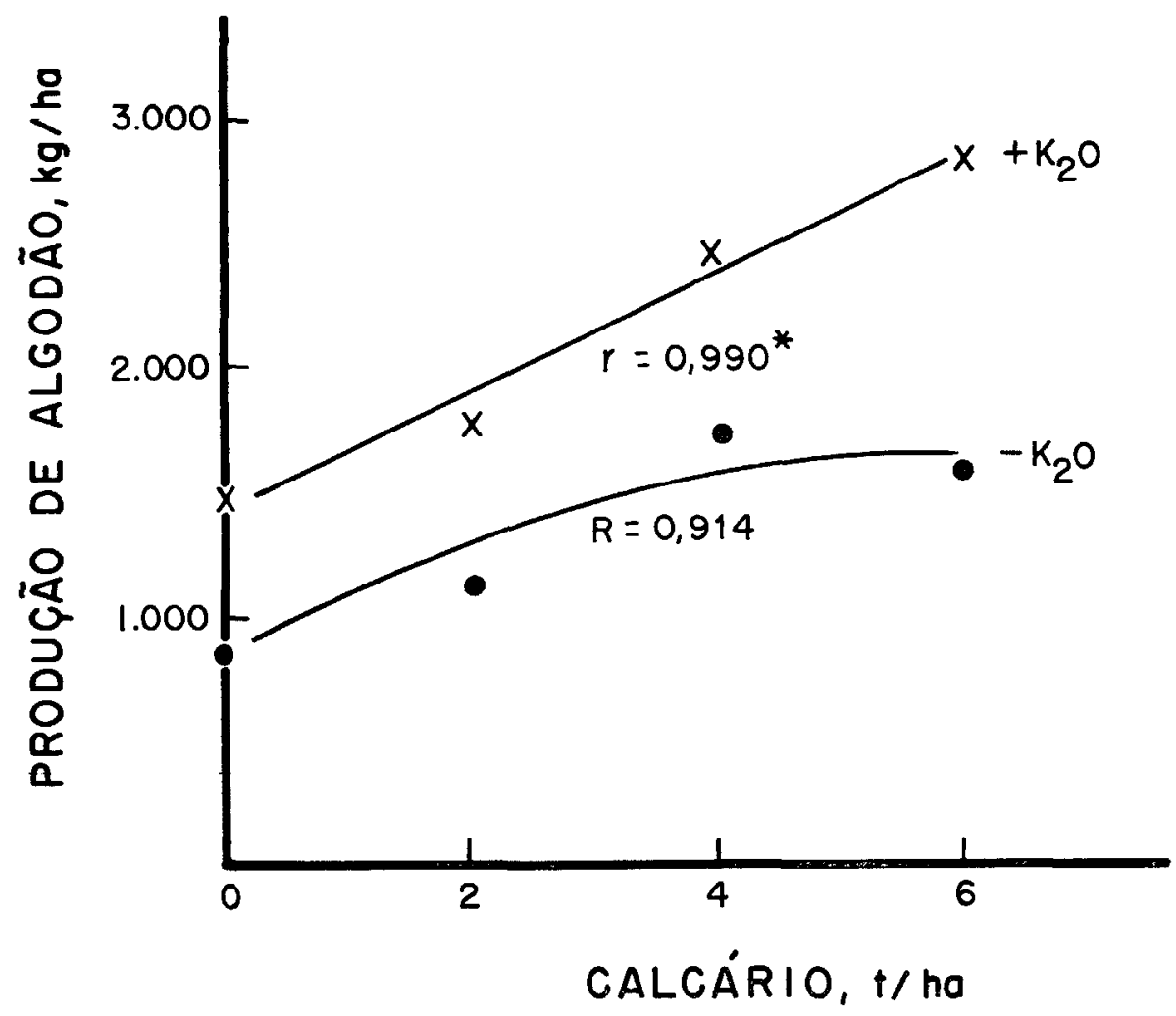

FIGURA 3. Influência da calagem na produção de algodão em caroço, na ausência ou na presença de potássio $\left(100 \mathrm{~kg} / \mathrm{ha}\right.$ de $\left.\mathrm{K}_{2} \mathrm{O}\right)$, médias de cinco anos sucessivos. 
quadro 2. Nos anos subseqüentes, com o acúmulo de potássio nos tratamentos adubados e com o esgotamento do nutriente nas parcelas testemunhas, o efeito da adubação se tornou evidente em todos os níveis de calagem.

Na figura 4, pode-se observar o efeito médio da adubação potássica na ausência e na presença da dose máxima de calcário. Sem a devida correção da acidez, a produção máxima esperada estaria na faixa de $1.503 \mathrm{~kg} / \mathrm{ha}$ de algodão em caroço, e seria obtida com o uso de $86 \mathrm{~kg} / \mathrm{ha}$ de $\mathrm{K}_{2} \mathrm{O}$. Com a calagem, um máximo de produção da ordem de $2.793 \mathrm{~kg} / \mathrm{ha}$ seria observado com a aplicação de $104 \mathrm{~kg} / \mathrm{ha}$ de $\mathrm{K}_{2} \mathrm{O}$. . Note-se que nas parcelas testemunhas, a relação $\left(\mathrm{Ca}^{2+}+\mathrm{Mg}^{2+} / \mathrm{K}^{+}\right)$, calculada para índices médios de análise de terra, esteve em torno de 12, enquanto nos canteiros corrigidos foi da ordem de 31 .

Tais resultados confirmam observações colhidas em trabalhos anteriores que demonstram estar a resposta do algodoeiro a potássio muito relacionada ao equilíbrio de bases $(4,13)$, ou mesmo ao equilíbrio catiònico do solo (3).

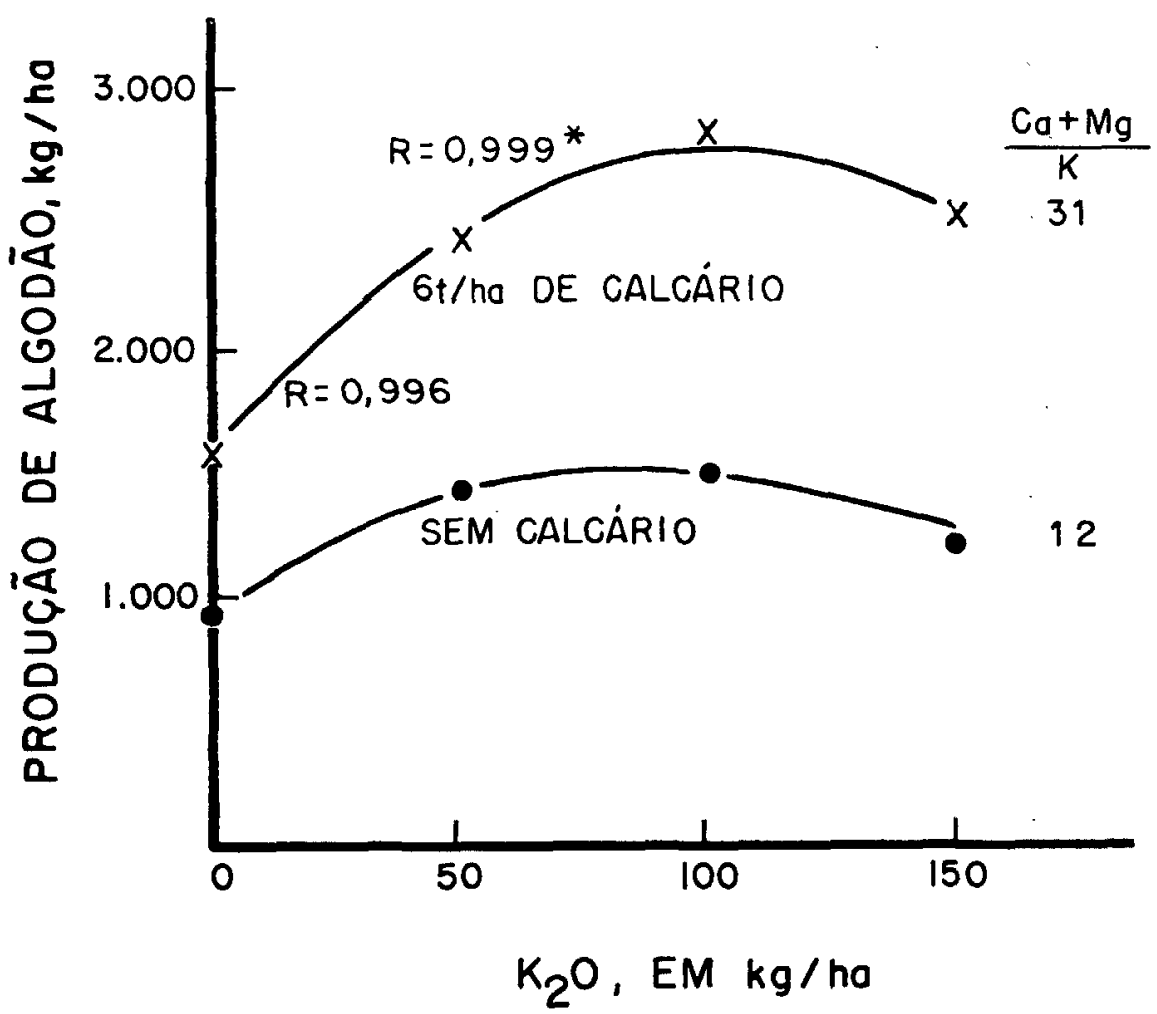

FIGURA 4. Influência da adubação potássica sobre a produção de algodão em caroço, em função do equilíbrio de bases do solo. Médias de cinco anos sucessivos. 


\subsection{Análise Foliar}

A calagem afetou com maior freqüência as concentrações de $\mathrm{K}$, Ca, $\mathrm{Mg}$ e $\mathrm{Mn}$ do limbo de folhas colhidas durante o florescimento das plantas, conforme resultados do quadro 3 .

QUADRO 3. Concentrações médias de macronutrientes e de micronutrientes mais influenciados pela calagem em quatro anos de ensaio de campo, em análises do limbo de quintas folhas de algodoeiro

\begin{tabular}{|c|c|c|c|c|c|c|}
\hline \multirow{2}{*}{ Calcário } & \multicolumn{6}{|c|}{ Elementos } \\
\hline & $\mathbf{P}$ & $\mathrm{K}$ & $\mathrm{Ca}$ & $\mathbf{M g}$ & Mn & $\mathrm{Cl}$ \\
\hline \multirow[t]{2}{*}{ t/ha } & \multicolumn{4}{|c|}{$-\%$} & \multirow[t]{2}{*}{ ppr } & $\mathrm{m}=$ \\
\hline & \multicolumn{4}{|c|}{$1977 / 782^{\circ}$ ano agrícola) } & & \\
\hline 0 & $0,233 \mathrm{~b}(1)$ & 1,46 & $1,94 \mathrm{~b}$ & 0,51 & $256 \mathrm{a}$ & \\
\hline 2 & $0,248 \mathrm{ab}$ & 1,57 & $2,11 \mathrm{~b}$ & 0,51 & $201 b$ & \\
\hline 4 & $0,240 \mathrm{ab}$ & 1,42 & $2,28 \mathrm{ab}$ & 0,57 & $204 b$ & \\
\hline 6 & $0,266 \mathrm{a}$ & 1,38 & $2,60 \mathrm{a}$ & 0,67 & $197 \mathrm{~b}$ & \\
\hline$\ll \mathbf{F} »$ & $4,77 * *$ & $2,46 \mathrm{NS}$ & $11,20 *$ & $2,31 \mathrm{NS}$ & $6,45^{* *}$ & \\
\hline \multirow[t]{2}{*}{$\mathrm{CV} \%$} & 10,7 & 14,4 & 15,2 & 34,4 & 20,4 & \\
\hline & \multicolumn{5}{|c|}{$1978 / 79$ ( $3^{\circ}$ ano agrícola $)$} & \\
\hline 0 & 0,276 & 0,98 & $2,37 a b$ & $0,50 \mathrm{~b}$ & $416 a$ & \\
\hline 2 & 0,261 & 0,92 & $2,17 \mathrm{~b}$ & $0,54 b$ & $307 \mathrm{~b}$ & \\
\hline 4 & 0,286 & 0,86 & $2,56 a b$ & $0,70 \mathrm{a}$ & $307 b$ & \\
\hline 6 & 0,290 & 0,84 & $2,81 \mathrm{a}$ & $0,74 a$ & $278 \mathrm{~b}$ & \\
\hline$\ll \mathbf{F} »$ & $0,93 \mathrm{NS}$ & $0,58 \mathrm{NS}$ & $3,59 *$ & $10,67 * *$ & $4,03 *$ & \\
\hline \multirow[t]{2}{*}{ CV\% } & 18,7 & 35,8 & 23,3 & 23,1 & 37,1 & \\
\hline & \multicolumn{6}{|c|}{$1979 / 80\left(4^{\circ}\right.$ ano agricola $)$} \\
\hline 0 & 0,242 & $1,63 \mathrm{~b}$ & $2,40 \mathrm{~b}$ & $0,49 \mathrm{~b}$ & $357 \mathrm{a}$ & 3384 \\
\hline 2 & 0,252 & $1,82 \mathrm{ab}$ & $2,36 \mathrm{~b}$ & $0,55 a b$ & $255 \mathrm{ab}$ & 3029 \\
\hline 4 & 0,268 & $1,92 \mathrm{a}$ & $2,54 a b$ & $0,64 a b$ & $229 \mathrm{~b}$ & 3522 \\
\hline 6 & 0,261 & $1,73 \mathrm{ab}$ & $2,93 a$ & $0,73 a$ & $192 \mathrm{~b}$ & 2886 \\
\hline$\ll \mathbf{E} »$ & $1,02 \mathrm{NS}$ & $3,75 *$ & $6,25 * \%$ & $5,86^{* *}$ & $10,38^{*}$ & $1,35 \mathrm{NS}$ \\
\hline \multirow[t]{2}{*}{ CV\% } & 17,6 & 14,5 & 13,4 & 28,3 & 34,2 & 32,0 \\
\hline & \multicolumn{6}{|c|}{$1980 / 81$ (5 ano agrícola) } \\
\hline 0 & 0,311 & $1,51 \mathrm{a}$ & 2,03 & $0,48 \mathrm{c}$ & $512 a$ & 5103 \\
\hline 2 & 0,302 & $1,54 a$ & 1,90 & $0,52 \mathrm{bc}$ & $370 a b$ & 5159 \\
\hline 4 & 0,300 & $1,44 \mathrm{ab}$ & 1,94 & $0,57 \mathrm{ab}$ & $329 b$ & 4695 \\
\hline 6 & 0,294 & $1,30 \mathrm{~b}$ & 2,12 & $0,62 a$ & $311 b$ & 4959 \\
\hline$\ll \mathbf{F} »$ & 0,35 & $7,43 * *$ & $2,86 \mathrm{NS}$ & $9,46 * *$ & $6,43^{* *}$ & $0,63 \mathrm{NS}$ \\
\hline $\mathrm{CV} \%$ & 15,3 & 10,8 & 11,9 & 14,4 & 37,9 & 21,0 \\
\hline
\end{tabular}

(1) Letras não comuns simbolizam classes estatísticas diferentes, pelo teste de Tukey, a $5 \%$. 
Como era esperado, a calagem concorreu para aumentar as concentraçôes de $\mathrm{Ca}$ e de $\mathrm{Mg}$ e para diminuir as de $\mathrm{K}$ e de $\mathrm{Mn}$; $\mathrm{Fe}$ e $\mathrm{Al}$, entretanto, não foram afetados significativamente, como ocorreu em trabalho anterior (14). Apenas no segundo ano agrícola, a concentração de fósforo cresceu de modo sensível com a aplicação do correiivo, em razão talvez do alto nível de adubação anual $\left(100 \mathrm{~kg} /\right.$ ha de $\left.\mathrm{P}_{2} \mathrm{O}_{5}\right)$.

Foi observado destacado aumento na concentração de potássio do limbo foliar em decorrência da aplicação de adubo (quadro 4), embora essa parte da folha nem sempre demonstre a mesma sensibilidade do peciolo para diagnose da nutrição potássica do algodoeiro $(5,15)$. Confirmam-se, assim, vários resultados obtidos no mesmo sentido $(\mathbf{3}, \mathbf{5}, \mathbf{1 5})$.

QUADRO 4. Concentrações médias de macronutrientes e de micronutrientes mais influenciados pela adubação potássica em quatro anos de ensaio de campo, em análises do limbo de quintas folhas de algodoeiro

\begin{tabular}{|c|c|c|c|c|c|c|}
\hline \multirow{2}{*}{$\mathrm{K}_{2} \mathrm{O}$} & \multicolumn{6}{|c|}{ Elementos } \\
\hline & $\mathrm{P}$ & $\mathrm{K}$ & $\mathrm{Ca}$ & Mg & $\mathrm{Mn}$ & $\mathrm{Cl}$ \\
\hline \multirow[t]{2}{*}{$\mathrm{kg} / \mathrm{ha}$} & \multicolumn{4}{|c|}{$\%$} & --- ppm & $m \longrightarrow$ \\
\hline & \multicolumn{5}{|c|}{$1977 / 78$ ( $2^{\circ}$ ano agrícola $)$} & \\
\hline 0 & 0,258 & $0,98 \mathrm{c}$ & $2,39 \mathrm{a}$ & 0,62 & $188 \mathrm{~b}$ & \\
\hline 50 & 0,245 & $1,50 \mathrm{~b}$ & $2,32 \mathrm{a}$ & 0,55 & $208 \mathrm{~b}$ & \\
\hline 100 & 0,239 & $1,59 a b$ & $2,14 \mathrm{~b}$ & 0,53 & $214 a b$ & \\
\hline 150 & 0,245 & $1,74 \mathrm{a}$ & $2,08 \mathrm{~b}$ & 0,56 & $248 \mathrm{a}$ & \\
\hline$\langle\mathrm{F} »$ & $2,07 \mathrm{NS}$ & $67,80^{*} *$ & $5,47 *$ & $1,25 \mathrm{NS}$ & $8,92 * *$ & \\
\hline \multirow[t]{2}{*}{ CV\% } & 9,3 & 11,0 & 11,4 & 25,7 & 15,8 & \\
\hline & \multicolumn{5}{|c|}{$1978 / 79\left(3^{\circ}\right.$ ano agrícola $)$} & \\
\hline 0 & 0,287 & $0,56 \mathrm{c}$ & $2,83 a$ & $0,75 a$ & $293 c$ & \\
\hline 50 & 0,270 & $0,86 \mathrm{~b}$ & $2,36 \mathrm{~b}$ & $0,57 \mathrm{~b}$ & $308 \mathrm{bc}$ & \\
\hline 100 & 0,277 & $1,03 a b$ & $2,40 \mathrm{~b}$ & $0,59 \mathrm{~b}$ & $330 a b$ & \\
\hline 150 & 0,278 & $1,16 \mathrm{a}$ & $2,33 \mathrm{~b}$ & $0,57 \mathrm{~b}$ & $378 \mathrm{a}$ & \\
\hline$\ll \mathbf{F} »$ & $0,80 \mathrm{NS}$ & $34,10 \%$ & $8,81^{* *}$ & $18,97 * *$ & $5,46^{* *}$ & \\
\hline \multirow[t]{2}{*}{$\mathrm{CV} \%$} & 11,1 & 19,5 & 12,8 & 12,9 & 19,4 & \\
\hline & \multirow{2}{*}{\multicolumn{5}{|c|}{$\begin{array}{c}1979 / 80 \text { ( } 4^{\circ} \text { ano agrícola) } \\
102 \mathrm{~d} \quad 2,76 \mathrm{a}\end{array}$}} & \\
\hline 0 & & $1,02 \mathrm{~d}$ & $2,76 \mathrm{a}$ & $0,74 \mathrm{a}$ & $220 \mathrm{~b}$ & $810 d$ \\
\hline 50 & 0,259 & $1,78 \mathrm{c}$ & $2,56 a b$ & $0,63 \mathrm{~b}$ & $240 \mathrm{~b}$ & $2274 \mathrm{c}$ \\
\hline 100 & 0,250 & $1,93 \mathrm{~b}$ & $2,43 a b$ & $0,58 b$ & $255 b$ & $3236 \mathrm{~b}$ \\
\hline 150 & 0,253 & $2,37 a$ & $2,37 \mathrm{~b}$ & $0,48 \mathrm{c}$ & $319 a$ & $6473 a$ \\
\hline$\ll \mathbf{F} »$ & $1,22 \mathrm{NS}$ & $62,32^{* *}$ & $3,94 *$ & $49,30 * *$ & $10,91 *:$ & 181,66 \\
\hline \multirow[t]{2}{*}{$\mathrm{CV} \%$} & 6,7 & 16,1 & 13,5 & 10,1 & 20,2 & 22,2 \\
\hline & \multicolumn{5}{|c|}{$1980 / 81$ (5 $5^{\circ}$ ano agrícola) } & \\
\hline 0 & $0,321 \mathrm{a}(1)$ & $1,05 \mathrm{c}$ & $2,19 \mathrm{a}$ & $0,62 \mathrm{a}$ & $342 \mathrm{~b}$ & $1553 d$ \\
\hline 50 & $0,297 \mathrm{ab}$ & $1,40 \mathrm{~b}$ & $2,01 \mathrm{~b}$ & $0,55 \mathrm{~b}$ & $360 \mathrm{~b}$ & $4704 \mathrm{c}$ \\
\hline 100 & $0,288 \mathrm{~b}$ & $1,52 \mathrm{~b}$ & $1,91 \mathrm{~b}$ & $0,53 \mathrm{~b}$ & $373 b$ & $5849 b$ \\
\hline 150 & $0,301 \mathrm{ab}$ & $\overrightarrow{\mathrm{i}}, 8 \mathrm{1a}$ & $1,89 b$ & $0,48 \mathrm{c}$ & $445 \mathrm{a}$ & $7810 \mathrm{a}$ \\
\hline$\langle F\rangle$ & $3,00^{*}$ & $85,75 * *$ & $11,46 * *$ & $24,10 * *$ & $11,93 *$ & $105,95 *$ \\
\hline $\mathrm{CV} \%$ & 10,8 & 9,4 & 8,0 & 8,9 & 13,8 & 20,4 \\
\hline
\end{tabular}

(1) Letras não comuns simbolizam classes estatisticas diferentes pelo teste de Tukey, a $5 \%$. 
Pela análise do quadro em questão, nota-se que as concentrações de $\mathrm{Ca}$ e de $\mathrm{Mg}$ diminuíram sempre com a adubação potássica. $\mathrm{O}$ antagonismo entre $\mathrm{K}$ e $\mathrm{Ca} \mathrm{e} / \mathrm{ou} \mathrm{Mg}$, tem sido citado com freqüência em pesquisas com o algodoeiro $(5,7,8,15)$. Entretanto, um aspecto inexplorado se refere ao aumento sistemático de $\mathrm{Cl}$ e de $\mathrm{Mn}$, conseqüente da aplicação de cloreto. Em especial, a produtividade guardou uma estreita correlação com a concentração de $\mathrm{Cl}$ no limbo, conforme figura 5 . Percebe-se que após um determinado nível de concentração, a produtividade começa a declinar, refletindo talvez o início de uma situação de toxicidade. Embora não tenham sido observados sintomas externos de fitotoxidade devidos a esse elemento, em novos estudos semelhantes a este poderiam ser testadas outras fontes de potássio.

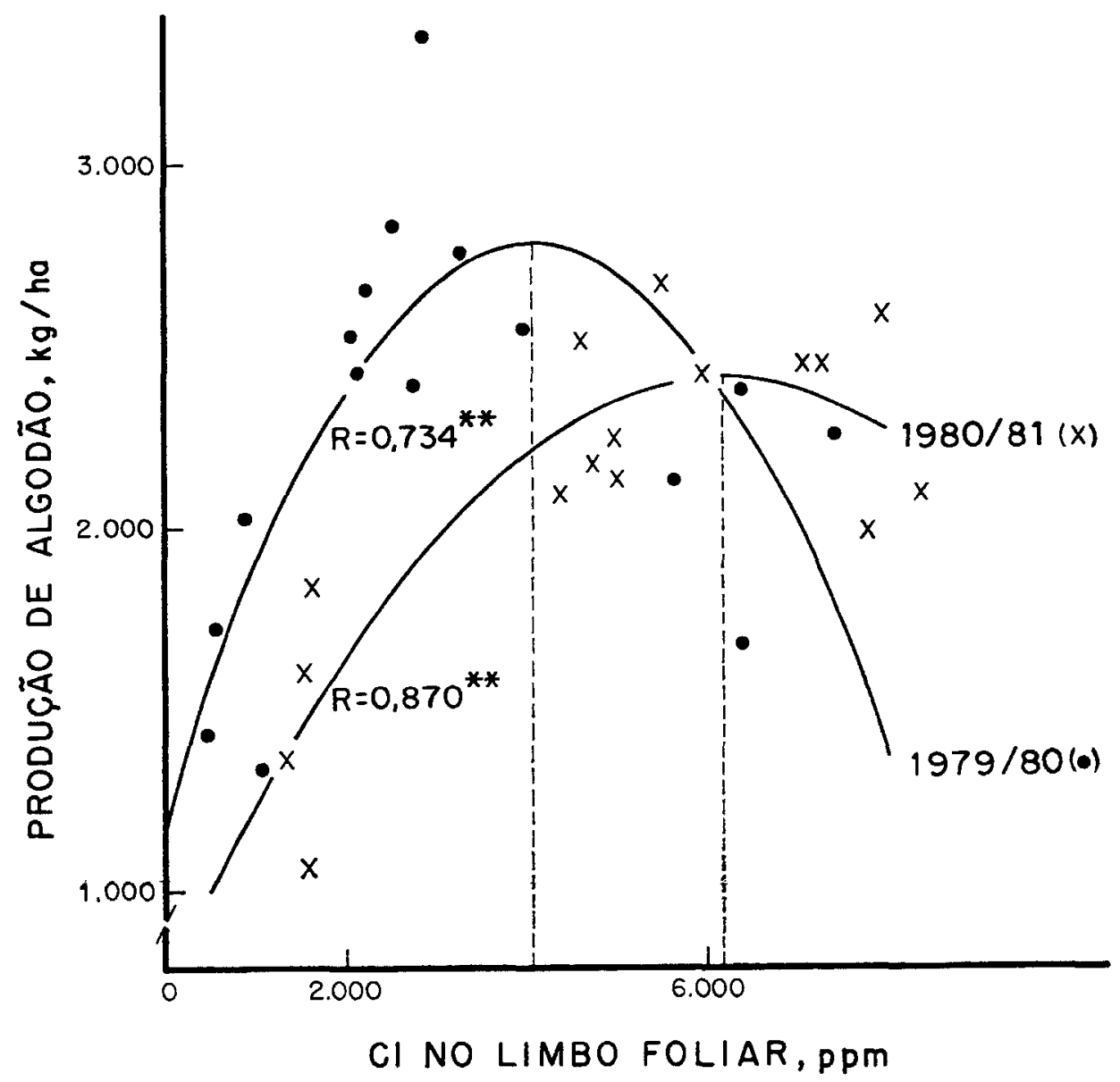

FIGURA 5. Relação entre concentração de $\mathrm{Cl}$ no limbo foliar e produção de algodão em caroço, observada no quarto e quinto anos agrícolas, em ensajo permanente de calagem e adubação anual com cloreto de potássio. 


\section{CONCLUSÕES}

Do exposto no presente trabalho, podem ser destacados os seguintes aspectos:

a) Considerando o excelente efeito do calcário, utilizado em dose de até $6 \mathrm{t} / \mathrm{ha}$, o método de recomendação de calagem visando apenas neutralizar o Al trocável do solo, se aplicado no presente caso, teria levado a uma dose insuficiente do corretivo, devido ao baixo teor do elemento revelado na análise original do solo $\left(0,3 \mathrm{meq}\right.$ de $\mathrm{Al}^{3+} / 100 \mathrm{~cm}^{3}$ de T.F.S.A.).

b) $\mathrm{Na}$ dose máxima, a calagem elevou consideravelmente a soma de $\mathrm{Ca}^{2+}+\mathrm{Mg}^{2+}$ e o $\mathrm{pH}$ da camada arável do solo, mantendo esse índice na faixa de 5,8-6,0 até o quinto ano. A produtividade das plantas mostrou-se estreitamente correlacionada com as referidas características.

c) Na ausência de potássio, o efeito do calcário sobre a produção do algodoeiro mostrou-se limitado, enquanto na presença de dose adequada desse nutriente, sua ação foi de natureza linear.

d) A reação das plantas a cloreto de potássio foi mais acentuada na presença de calcário, confirmando a importância de considerar o equilíbric de bases no critério de recomendação de adubação potássica do algodoeiro.

e) A calagem contribuiu para aumentar as coneentraçōes de Ca e de $\mathrm{Mg}$ do limbo foliar e para diminuir $\mathrm{K}$ e $\mathrm{Mn}$. Ao contrário, a aplicação de cloreto de potássio provocou decréscimo de $\mathrm{Ca}$ e $\mathrm{Mg}$ e aumento de $\mathrm{K}, \mathrm{Mn}$ e $\mathrm{Cl}$.

\section{SUMMARY}

\section{EFFECT OF LIMING AND POTASSIUM FERTILIZATION ON COTTON}

An inadequate potassium fertilization for the cotton crop may limit, eventualiy, the effect of liming in the correction of the acidity of certain soils, due to the unbalance of bases. With the purpose of clearing up this problem, a field experiment with lime and potassium applications was conducted on a Dystrophic Dusky Red Latosol. During five following years, a linear effect of dolomitic limestone $(2,4$ and 6t/ha) upon cotton yield was noted, in the presence of adequate potassium fertilization; without potassium, liming effect was quadratic. At the highest liming, the level of soil pH increased from 5.1 to 5.8-6.0 and soil calcium plus magnesium content from 1.1 to $3.0-3.2 \mathrm{meq} / 100 \mathrm{~cm}^{3}$ soil. Cotton yield was highly correlated with $\mathrm{pH}$ as well as with soil $\mathrm{Ca}^{2+}+\mathrm{Mg}^{2+}$ content. $\mathrm{Ca}$ and $\mathbf{M g}$ concentrations in the leaf blade increased with liming, while those of $\mathrm{K}$ and $\mathrm{Mn}$ decreased. The effect of potassium fertilization $(50,100$ and $150 \mathrm{~kg} / \mathrm{ha}$ of $\mathrm{K}, \mathrm{O})$ on cotton yicld was quadratic and maximun at the highest liming level. It was observed that leaf $\mathrm{Ca}$ and $\mathrm{Mg}$ concentrations decreased with fertilization, while leaf $\mathrm{K}, \mathrm{Mn}$ and $\mathrm{Cl}$ concentrations increased. Cotton yield was significantly correlated with leaf $\mathrm{Cl}$ concentration. It seems possible that, at high potassium chloride levels, chlorine texicity may occur in the plants. 


\section{REFERENCIAS BIBLIOGRÄFICAS}

1. COLEMAN, N.T.; KAMPRATH, E.J.; WEED, S.D. Liming. Advances in Agronomy, 10:475-522, 1958.

2. FERRAZ, C.A.M. Efeitos de calcário, fósforo e potássio na produtividade do algodoeiro (Gossypium hirsutum L.) em Latossolo Roxo. Botucatu, Faculdades de Ciências Médicas e Biológicas, 1973. 70p. Tese. (Doutoramento)

3. FREITAS, L.M.M.; MCCLUNG, A.C.; PIMENTEL GOMES, F. Determinação das áreas deficientes em potássio para a cultura de algodão. Fertilité, 26:37-47, 1966.

4. FUzATTO, M.G. \& FERRAz, C.A.M. Correlação entre o efeito da adubação potássica. no algođoeiro e a análise química do solo. Bragantia, Campinas, $26(26): 345-352,1967$.

5. HIROGE, R.; SILVA, N.M.; NAGAI, V.; BATAGLIA, O.C.; GALLO, J.R. Diagnose da nutrição nitrogenada e potássica do algodoeiro (Gossypium hirsutum ('IAC 13-1') pela análise química foliar. Ciência e Cultura, São Paulo, 28(1):51-56, 1976.

6. KAMPRATH, E.J. Exchangeable aluminum as a criterion for liming leachead mineral soils. Soil Science Society of America Proceedings, 34:252-254, 1970.

7. MELLO, F.A.P. A relação $\mathrm{K} / \mathrm{Mg}$ em folhas de algodoeiro cu'tivado em condições de campo. Anais da Escola Superior de Agricultura "Luiz de Queiroz», Piracicaba, 19:67-74, 1962.

8. PAGE, A.L. \& BINGHAM, F.T. Potassium-magnesium, interrelationships in cotton. California Agriculture, $19(11): 6-7,1965$.

9. QUAGGIO, J.A.; DECHEN, A.R.; RAIJ, B. van. Efeitos da aplicação de calcário e gesso sobre a produção de amendoim e lixiviação de bases no solo. Revista Brasileira de Ciência do Solo, Campinas, 6(3):189-194, 1982.

10. - - MASCARENHAS, H.A.A.; BATAGLIA, O.C. Resposta da soja ì aplicação de doses crescentes de calcário em Latossolo Roxo distrófico de cerrado. II - Efeito residual. Revista Brasileira de Ciência do Solo, Campinas, 6(2):113-118, 1982.

11. RATJ, B. van; CAMARGO, A.P.; MASCARENHAS, H.A.A.; FIROCE, R.; FEITOSA, C.T.; NERY, C.; LAUN, C.R.P. Efeitos de níveis de calagem na produção de soja em solo de cerrado. Revista Brasileira de Ciência do Solo, Campinas, 1(1):28-31, 1977.

12. SILVA, N.M. Acidez do solo e calagem para o algodoeiro. In: ACIDEZ e calagem no Brasil. Campinas, Sociedade Brasileira de Ciêncix do Solo, 1983. p.259-276.

13. - - Importância da seleção de gleba para estudos de adubação do algodoeiro. Campinas, Instituto Agronômico, 1971. 11p. (Projeto BNDE/ /ANDA/CIA-Publicação, 8)

14. - : FERRAZ, C.A.M.; RODRIGUES FILHO, F.S.O.; HIROCE, R. Emprego de calcário e de superfosfato simples na cultura do aigodoeiro em solo argiloso ácido. Bragantia, Campinas, 39(6):39-50, 1980.

15. ; HIROCE, R.; FUZATTO, M.G. Efeito da adubação sobre o desenvolvimento e a produção de duas variedades paulistas de algodoeiro em Latossolo Roxo intensamente cultivado. Campinas, Instituto Agronômico, 1971. 8p. (Projeto BNDE/ANDA/CIA-Publicação, 5) 